\title{
Knowledge and Attitude About Research Ethics Among Iranian Dental Students
}

\author{
Molook Torabi ${ }^{1,2}\left(\mathbb{D}\right.$, Arash Shahravan ${ }^{3}\left(\mathbb{D}\right.$, Marzieh Karimi Afshar ${ }^{1,4}\left(\mathbb{D}\right.$, , Yasaman Shenasa ${ }^{5}$, Mina \\ Mobasher6(10)
}

\begin{abstract}
${ }^{1}$ Kerman Social Determinants of Oral Health Research Center, School of Dentistry, Kerman University of Medical Sciences, Kerman, Iran.

${ }^{2}$ Department of Maxillofacial Pathology, School of Dentistry, Kerman University of Medical Sciences, Kerman, Iran.

${ }^{3}$ Department of Endodontics, School of Dentistry, Kerman University of Medical Sciences, Kerman, Iran.

${ }^{4}$ Department of Orthodontics, School of Dentistry, Kerman University of Medical Sciences, Kerman, Iran.

${ }^{5}$ School of Dentistry, Kerman University of Medical Sciences, Kerman, Iran.

${ }^{6}$ Department of Medical Ethics and History of Medicine, Faculty of Iranian Traditional Medicine, Kerman University of Medical Sciences, Kerman, Iran.
\end{abstract}

Correspondence: Marzieh Karimi Afshar, Orthodontics Department, School of Dentistry, Kerman University of Medical Sciences, Shafa Ave, Jomhoori Islami BLVD, Kerman 7618759689, Iran. E-mail: marzieh.k.afshar@gmail.com

Academic Editor: Mohammad Khursheed Alam

Received: 10 June 2020 / Review: 03 September 2020 / Accepted: 19 January 2021

How to cite: Torabi M, Shahravan A, Afshar MK, Shenasa Y, Mobasher M. Knowledge and attitude about research ethics
among Iranian dental students. Pesqui Bras Odontopediatria Clín Integr. 2021; $21: e 0127$.
https://doi.org/10.1590/pboci.2021.081

\begin{abstract}
Objective: To evaluate the knowledge and attitude of the students of Kerman dental school (Iran) about ethics in dental research. Material and Methods: This cross-section study was conducted on 307 dental students selected through the census sampling method. Data were collected by a researcher-made questionnaire consisting of 12 items about knowledge and 17 items about attitude toward research ethics. Data analyzed in SPSS software using t-test and linear regression test. P-values of less than 0.05 were considered statistically significant. Results: Of the respondents, $33.9 \%$ were male and $66.1 \%$ were female, and $44 \%$ had good knowledge and $20.8 \%$ had a positive attitude about research ethics. A significant correlation was found between knowledge and attitude. A significant correlation was also observed between knowledge and participation in research workshops. Knowledge and attitude showed no significant correlation with gender or year of admission. Conclusion: Participants had appropriate knowledge and attitude about research ethics. There is some room for improvement in research ethics education concerning experimental works and retrospective studies on biologic samples. Holding research workshops with an introduction to ethical codes of research is recommended.
\end{abstract}

Keywords: Bioethics; Ethics, Research; Health Knowledge, Attitudes, Practice; Students, Dental. 


\section{Introduction}

The past decades have seen rapid progress in dental research with significant contributions to oral health and public health in general [1]. In many cases, health researchers have to use human participants in their studies, which brings up ethical requirements for protecting the rights, dignity, and well-being of participants [Q].

There are numerous ethical and legal requirements for clinical research, which must be given the highest priority to ensure that participating patients are completely protected. This is especially important when working with vulnerable groups such as children and patients who cannot complete the consent form. Despite the global acceptance of the ethical guidelines stated in the Declaration of Helsinki [3], it is still possible to encounter violations and dishonesty in adhering to these requirements [4]. The act of acquiring informed consent is an essential prerequisite for any biomedical research involving diagnosis and treatment because, without it, the dentist will be vulnerable to litigation [5].

A study by Deolia et al. [6] on research ethics in India showed that dental professionals had a good attitude toward the issue, but there was room for improvement in their knowledge and behavior. This study also reported a statistically significant association between attitude toward the issue and age and gender [6]. In a study carried out by Mallela et al. [7] on research ethics in northern India, more than $90 \%$ of the participants were aware of ethics committees' presence but had little knowledge about international ethical guidelines. Also, $20 \%$ of the participants believed that research ethics committees cause delays in research [7].

According to Kakar et al. [8], informed consent is even more critical when providing medical care to children and foreigners and using medical images in medical and dental research. In the research conducted by Taiwo and Kass [9] in Nigeria on the people involved in oral health research, $93.8 \%$ of the respondents said they were not asked whether they want to volunteer, and all of them generally had poor knowledge about the key items of informed consent. El-Dessouky et al. [10] also reported the low awareness of participants in dental research. In a study by Ghaderi et al. [11], university instructors and professors had moderate knowledge and post-graduate students had poor knowledge about research's ethical guidelines.

Considering the involvement of biomedical research with human studies and the general scarcity of information in this regard, especially in dental field in Iran, and in continuing our interest in medical research $[12,13]$, the present study aimed to assess the knowledge and attitude of Kerman Medical University dental students about research ethics.

\section{Material and Methods}

\section{Study Design and Sample}

This descriptive cross-sectional study was performed through a census sampling method. All students of Kerman dental school (capital city of Kerman province in South, Eastern of Iran) were included. First, a list of college students in the academic year was prepared, and briefing sessions were held at the theoretical classrooms of students of each entrance classroom by an assistant (a senior dentistry student) with sufficient knowledge about the questionnaire and the aim of the study. In these sessions, research objectives were explained and verbal consent was obtained. It was also explained that participation is completely optional and responses with be anonymous.

\section{Data Collection}


Questionnaires were administered and collected at the same session. The approximate time for completing the questionnaire was 15 minutes. The questionnaire consisted of three parts. The first part was dedicated to collecting information about the student's demographic characteristics, including gender, year of admission, participation in research methodology workshops, participation in ethics workshops, published papers, and research proposals. The second part included 12 questions measuring the students' knowledge about ethical requirements of dental research (about the Declaration of Helsinki, health requirements of participants, research purpose, intervention complications, informed consent, informing participants of results, use of human data or materials such as blood, saliva and extracted teeth, approval of the ethics committee). For this part of the questionnaire, correct answers were awarded a score of 1 and wrong answers were given a score of 0 . Therefore, the total score of this part ranged from 0 to 12. The third part of the questionnaire comprised of 17 questionnaires measuring the students' attitude toward ethics in dental research (ethical considerations regarding laboratory samples, obtaining consent to perform radiography for research, obtaining informed consent for the use of saliva and blood, obtaining consent from vulnerable patients, such as the elderly or intellectually disabled). This part of the questionnaire was designed based on the 5-point Likert scale with answers ranging from completely disagreed to completely agree. Hence, the total score of this part ranged from 17 to 85 . For validity assessment verification, the questionnaire's initial draft was reviewed by a group of experts and modifications were made according to their comments. After a second review, experts verified the validity of the modified questionnaire. The validity coefficient of the questionnaire as a whole was estimated at 0.98 .

For reliability assessment, the questionnaire was administered to 20 students from different years of admission and the process was repeated two weeks later with the same 20 subjects. Based on this assessment, the reliability coefficient was calculated to 0.91 .

\section{Data Analysis}

Data were coded and entered into SPSS software, version 21 (IBM Corp., Armonk, NY, USA), and analyzed by linear regression and t-test at $\mathrm{p}<0.05$ significance level.

\section{Ethical Clearance}

This study was approved by the competent ethics committee with the ethics code IR.KMU.REC.1395.755.

\section{Results}

Of 307 students who participated in the research, 104 (33.9\%) were male and $199(64.8 \%)$ were female. One hundred and sixty-seven people (54.4\%) did not participate in research methodology workshops. Two hundred and forty people (78.2\%) had not taken the medical ethics course, and $36.2 \%(\mathrm{n}=111)$ were interested in participating in medical ethics workshops (Table 1).

Table 1. Distribution of respondents according to demographic variables.

\begin{tabular}{lcc}
\hline \multicolumn{1}{c}{ Variables } & N & \% \\
\hline Gender & & \\
Male & 104 & 33.9 \\
Female & 199 & 64.8 \\
No answer & 4 & 1.33 \\
Participated in research methodology workshops & &
\end{tabular}




\begin{tabular}{lcc} 
Yes & 140 & 45.6 \\
No & 167 & 54.4 \\
Participated in medical ethics course & 57 & 18.5 \\
Yes & 240 & 78.2 \\
No & & 21.5 \\
Had research proposals & 66 & 78.5 \\
$\quad$ Yes & 241 & 17.3 \\
No & & 82.8 \\
Published papers & 53 & \\
$\quad$ Yes & 254 & 40.1 \\
No & & 59.9 \\
Participated in scientific congresses & 123 & \\
Yes & 184 & 21.5 \\
No & & 78.5 \\
Participated in medical ethics workshops & 66 & \\
Yes & 241 & 36.2 \\
No & & 63.9 \\
Interested in taking the research ethics course & 111 & \\
Yes & 196 & \\
No & & \\
\hline
\end{tabular}

In the knowledge dimension, the item correctly answered most frequently was "physician is required to fully inform the patient about the possible complications of the research and how they must be addressed", which was answered correctly by 248 people (80.8\%). On the other hand, only 67 people (12.1\%) gave a correct answer to the item "declaration of Helsinki is about the ethical requirements of human research". Among the respondents, $62.2 \%$ gave a correct answer regarding the necessity of getting approval from ethics committees in all research projects and $70.7 \%$ correctly answered whether it is required to protect the confidentiality and privacy of research participants.

In the attitude dimension, $71.5 \%$ of the respondents disagreed or completely disagreed with the statement that "Dental research on people with an intellectual disability is allowed". After reading the statement, "It is required to obtain informed consent from patients before using blood samples in research (during and after taking samples)", 63.6\% of the student responded that they disagreed or completely disagreed with this statement. Among the respondents, $16.3 \%$ believed that it is not necessary to obtain informed consent to conduct research on the elderly, $44.9 \%$ agreed or completely agreed with the statement that there is no ethical consideration regarding the use of prepared dental blocks for research into dental materials, and $46.4 \%$ agreed or completely agreed with the statement that there is no ethical consideration regarding the use of extracted teeth in research.

The mean and standard deviation of the knowledge score was $7.43 \pm 2.99$ from 12. For attitude, the mean score was $39.47 \pm 10.05$ from 85 . Figure 1 shows the distribution of knowledge and attitude scores of the students. As can be seen, $40.4 \%$ of the students had good knowledge and $20.8 \%$ had a positive attitude about the issue.

A significant direct relationship was observed between the knowledge and attitude of the students $(\mathrm{p}=0.000)$. In this study, female students were more knowledgeable and had a more positive attitude about the ethics of dental research. In the case of knowledge, the difference between genders was statistically significant, although marginally $(p=0.077)$. In the case of attitude, the difference was not statistically significant $(p=0.41)$. Participation in research congresses was significantly related to knowledge $(p=0.010)$ but not attitude $(\mathrm{p}=0.706)$. There was a significant relationship between participation in ethics workshops and knowledge or 
attitude $(\mathrm{p}=0.529$ and $\mathrm{p}=0.291)$. Also, no statistically significant relationship was found between the students' knowledge and attitude and their admission year (Table 2).

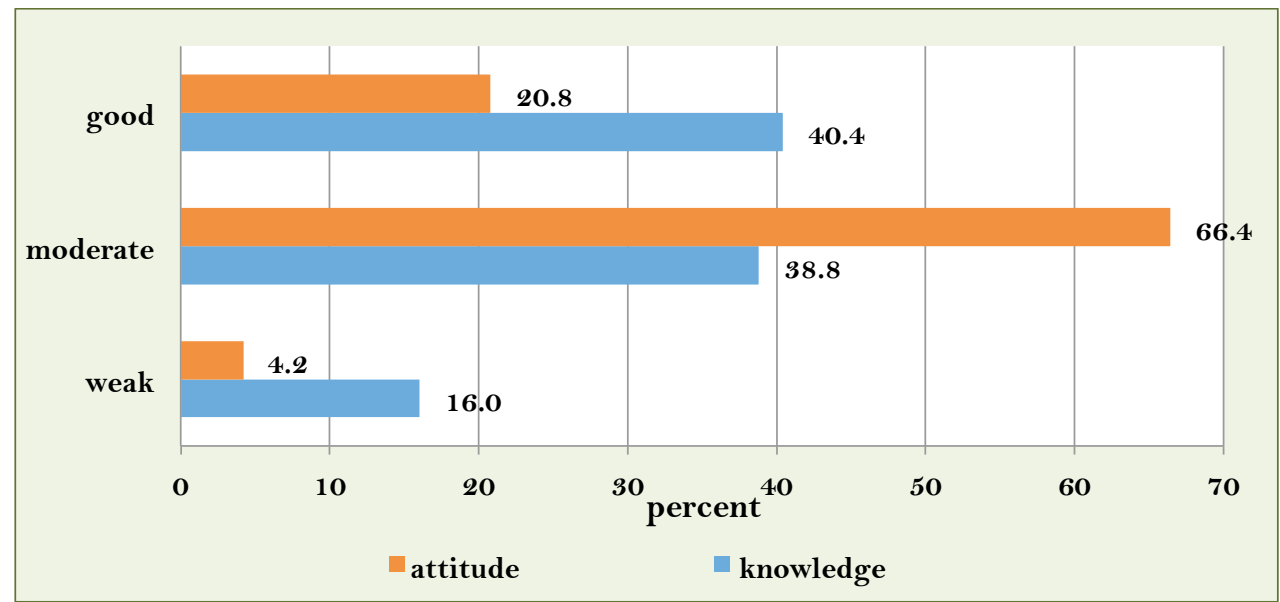

Figure 1. Distribution of knowledge and attitude scores of the students.

Table 2. Relationship between the students' knowledge and attitude and demographic variables.

\begin{tabular}{|c|c|c|c|c|c|}
\hline Variables & & & Mean & $\begin{array}{l}\text { Standard } \\
\text { Deviation }\end{array}$ & p-value \\
\hline \multirow{2}{*}{ Participated in research methodology workshops } & \multirow{2}{*}{ Knowledge } & Yes & 7.93 & 2.71 & \multirow{2}{*}{$0.010^{*}$} \\
\hline & & No & 7.02 & 3.16 & \\
\hline & \multirow{2}{*}{ Attitude } & Yes & 39.73 & 11.05 & \multirow{2}{*}{0.706} \\
\hline & & No & 39.26 & 9.22 & \\
\hline \multirow{4}{*}{ Participated in ethics workshops } & \multirow{2}{*}{ Knowledge } & Yes & 7.62 & 2.83 & \multirow{2}{*}{0.529} \\
\hline & & No & 7.37 & 3.06 & \\
\hline & \multirow{2}{*}{ Attitude } & Yes & 38.25 & 11.75 & \multirow{2}{*}{0.291} \\
\hline & & No & 39.88 & 9.41 & \\
\hline \multirow{4}{*}{ Had research proposals } & \multirow{2}{*}{ Knowledge } & Yes & 7.06 & 3.03 & \multirow{2}{*}{0.272} \\
\hline & & No & 7.53 & 2.90 & \\
\hline & \multirow{2}{*}{ Attitude } & Yes & 37.63 & 11.78 & \multirow{2}{*}{0.150} \\
\hline & & No & 40.02 & 9.49 & \\
\hline \multirow{4}{*}{ Published papers } & \multirow{2}{*}{ Knowledge } & Yes & 6.96 & 2.48 & \multirow{2}{*}{0.228} \\
\hline & & No & 7.52 & 3.04 & \\
\hline & \multirow{2}{*}{ Attitude } & Yes & 40.64 & 9.67 & \multirow{2}{*}{$0.000^{*}$} \\
\hline & & No & 33.85 & 9.87 & \\
\hline \multirow{4}{*}{ Participated in scientific congresses } & \multirow{2}{*}{ Knowledge } & Yes & 7.98 & 2.67 & \multirow{2}{*}{$0.042^{*}$} \\
\hline & & No & 7.16 & 3.17 & \\
\hline & \multirow{2}{*}{ Attitude } & Yes & 40.01 & 11.33 & \multirow{2}{*}{0.525} \\
\hline & & No & 39.19 & 9.17 & \\
\hline \multirow{4}{*}{ Participated in medical ethics workshops } & \multirow{2}{*}{ Knowledge } & Yes & 7.33 & 2.58 & \multirow{2}{*}{0.754} \\
\hline & & No & 7.46 & 3.04 & \\
\hline & \multirow{2}{*}{ Attitude } & Yes & 40.18 & 9.23 & \multirow{2}{*}{$0.051 *$} \\
\hline & & No & 36.72 & 12.46 & \\
\hline Interested in takino the research othics cource & Knowledme & Yes & 7.52 & 2.72 & 0680 \\
\hline mterested in taking the researcn etnics course & nnowleage & No & 7.37 & 3.15 & 0.680 \\
\hline & Attitude & Yes & 38.75 & 10.77 & 0.387 \\
\hline & Attitude & No & 39.87 & 9.64 & \\
\hline Gender & Knowledoe & Male & 7.03 & 3.30 & 0.077 \\
\hline Gender & hnowledge & Female & 7.69 & 2.81 & \\
\hline & Attitude & Male & 38.81 & 11.04 & 0041 \\
\hline & Attitude & Female & 39.89 & 9.56 & 0.041 \\
\hline
\end{tabular}




\section{Discussion}

In the present research, (12.1\%) knew that Helsinki's declaration is about ethical consideration of human research. In the study conducted by Mallela et al. [7], 34.8\% of the faculty members in northern India said they knew about this declaration's topic. Hariharan et al. [14] also reported that very few of their respondent were aware of this declaration.

It has been shown that researchers must be aware of the ethical and legal requirements of human research in their own country and at the international level [15]. The Council for International Organizations of Medical Sciences (CIOMS) guidelines consists of valuable content regarding the challenges of contemporary clinical research, complex issues such as HIV/AIDS research, the availability of treatments after the research, research on women, protection of privacy and confidentiality, compensation for undesirable outcomes and complications, and guidelines for obtaining consent [16].

In this research, $21.6 \%$ of the students had participated in research ethics workshops. In the study of El-Dessouky et al. [10], 36.8\% of respondents had participated in research ethics workshops or courses. Reddy et al. [1] reported that $67 \%$ of respondents had been educated about research ethics. Compared to the study of El-Dessouky et al. [10], a larger fraction of students surveyed in this study had participated in research ethics workshops and courses, which reflects the higher importance given to the topic at the surveyed university.

In this study, $36.1 \%$ of the students believed that "ethics committees often cause delays in research". This is consistent with the findings reported by El-Dessouky et al. [10], where $44 \%$ of respondents believed that ethics committees delay the research, but is higher than the $26 \%$ reported in the study of Reddy et al. [1] . In the research carried out by Gopinath et al. [15], 31\% of university instructors believed that ethical committees delay the research. Given that all research projects need the approval of ethics committees, this finding suggests that the process of obtaining this approval should be accelerated.

In the present study, $22.4 \%$ of the students agreed fully or partially that there is no need to inform patients about the materials used in human research, given their limited knowledge about the subject. In the study of El-Dessouky et al. [10], 10\% of respondents believed that patients need not be aware of the risk of research. Ethical guidelines, however, state that participants should be made aware of the nature of the research and its possible consequences and make a free choice without any concern about possible effects on their own treatment process [17].

In the present study, $63.3 \%$ and $55.7 \%$ of the respondents partially or completely disagreed with the necessity of obtaining consent for taking blood or gingival crevicular fluid samples for use in research. ElDessouky et al. [10] reported that about one-third of their respondents believed that consent is not necessary in such cases. Reddy et al. found that 94 of the 115 respondents partially or strongly agreed with this statement [1].

In our study, $16.3 \%$ and $13.3 \%$ of the students partially or completely agreed with the necessity of obtaining written consent from the elderly and intellectually disabled. In the study of El-Dessouky et al. [10], almost $40 \%$ of people believed that written consent should be obtained from vulnerable people. In this context, the term vulnerable groups refer to people who are relatively or completely unable to protect themselves, including psychological patients, intellectually disabled, prisoners, pregnant women, embryos, people with terminal diseases, students, elderly, and anesthetized people [17]. Helsinki's declaration states that "medical research with a vulnerable group is only justified if the research is responsive to the health needs or priorities of this group" [18]. 
More than 95\% of respondents in the study of Gopinath et al. [15] believed that informed consent should be obtained in writing from all patients to ensure they understand both benefits and risks of research. In the present study, $62.2 \%$ of the students partially or completely agreed that "It is necessary to obtain consent before performing radiography for research". In fact, the respondents agreed with this statement more than they did with any other statement, most likely because they were aware of the risks of radiation exposure.

In this survey, $40.4 \%$ of the respondents had a good level of knowledge about dental research ethics. However, knowledge about retrospective studies on pathology and biologic samples was tragically scarce. This finding suggests that universities and workshops should put more effort into closing the existing gap in the knowledge of students and researchers about the ethics of retrospective studies that use paraffin blocks or stored biologic samples. On the question that whether retrospective studies need to gain informed consent, the consensus in most countries is that these studies do not require written consent, provided that the issue is disclosed to and verified by the competent ethics committee [19].

In the present study, $16 \%$ of the students had poor knowledge and $38.8 \%$ had moderate knowledge about ethics in dental research. In the study of Gopinath et al. [15], 38\% of instructors had poor knowledge about this topic. Mallela et al. [7] reported that faculty members had a fair knowledge about research ethics. In a study carried out by Ghaderi et al. [11], the students of Kurdistan University showed higher than average knowledge about this subject.

In this study, there was a significant relationship between students' knowledge about ethics in dental research and their participation in scientific congress. The reason for this may be that many lectures given in scientific congresses are based on the principles of ethics in research and have been considered by the participating student.

There was a significant correlation between students' knowledge about ethics in dental research and their participation in research methodology workshops. The reason for this may be that ethical issues have been well discussed in research methodology workshops and have therefore raised awareness.

No significant relationship was observed between participation in ethics workshops and knowledge about ethics in dental research. This is perhaps because these workshops often involve more general principles of research than moral principles in particular.

There was a significant relationship between participation in ethics workshops and attitude about ethics in dental research. In some studies, the reason for this may be that the researcher does not have the necessary knowledge but has a positive attitude towards the observance of ethical principles.

In this study, $52.1 \%$ of the respondents partially or completely disagreed with the statement that "Verbal consent is enough for all human research". Obtaining informed consent before clinical trials is one of the basic principles of ethics in research. Kakar et al. [8] argue that informed consent is essential for providing medical care to children and foreigners and for using medical images in medical and dental research. A study carried out in Nigeria showed that $93.8 \%$ of the people who had participated in oral health research were not asked whether they want to volunteer, and all of them had generally poor knowledge about the key aspects of informed consent [9]. Informed consent is the foundation of ethics in medical and health care research. This issue is especially important for research on the elderly, where their poor health, cognitive impairments, and passiveness may complicate the situation [20].

It is not arguable that every adult has the right to decide whether or not to perform medical treatment, even if the refusal results in his/her death [21]. The systematic review carried out by Mukherjee et al. [20] showed that informed consent is a neglected subject in dental care and research the elderly. 
A significant direct relationship was observed between the students' attitude and knowledge about ethics in dental research, in the sense that more knowledgeable people had more positive attitudes. Thus, it seems in knowledgeable participants have been able to use their awareness to improve their attitude.

In this study, $20.8 \%$ of the participants had a positive attitude toward research ethics. In contrast, Kandeel et al. [22] reported that more than $80 \%$ of their respondents had a positive attitude toward ethics committees. It should, however, be noted that Kandeel's study was conducted on faculty members rather than students [22]. The study of Gopinath et al. [15] also reported that the attitude of participants about the ethics of research was not desirable.

The present research found a statistically significant relationship between attitude toward research ethics and having published a paper. This is perhaps because the process of writing and publishing a paper involves obtaining approval from competent ethics committees, which requires the researchers to educate themselves about the subject, thereby affecting their attitude.

There was no significant difference between male and female students in terms of attitude toward research ethics. Since ethics is an issue in developing, this lack of difference in attitude between genders is not unexpected.

However, female students had higher mean knowledge scores, although the difference was not significant $(p>0.05)$. This is perhaps because female students have paid more attention to ethics-related discussions in workshops and classes.

In this research, $36.2 \%$ of the students wanted to participate in research ethics workshops and there was no significant relationship between this inclination and attitude toward research ethics. In contrast, Gopinath's study reported that most of their respondents were inclined to participate in research ethics workshops [15]. This difference can be attributed to the fact that the participants in our study were university students.

\section{Conclusion}

Participants had appropriate knowledge and attitude about research ethics. Overall, there is much room for improvement in research ethics education, including those concerning experimental and laboratory works and retrospective studies on human samples.

\section{Authors' Contributions}

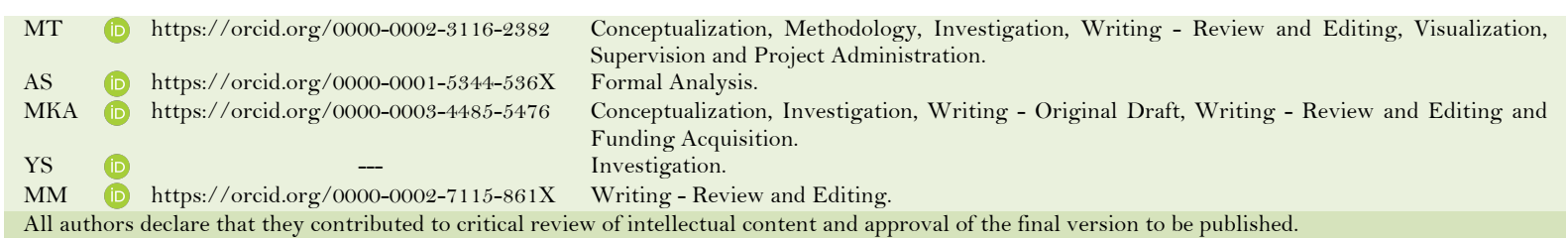

\section{Financial Support}

None.

\section{Conflict of Interest}

The authors declare no conflicts of interest.

\section{Data Availability}


The data used to support the findings of this study can be made available upon request to the corresponding author.

\section{References}

[1] Reddy RS, Ramya K, Raju AVKM, Rayudu GS, Kiran CS, Jyothirmai K. Knowledge, awareness and attitudes about research ethics among dental professionals in a dental institution of south India. J Educ Ethics Dent 2013; 3(1):34-9. https://doi.org/10.4103/0974-7761.126942

[Q] Puri KS, Suresh KR, Gogtay NJ, Thatte UM. Declaration of Helsinki, 2008: implications for stakeholders in research. J Postgrad Med 2009; 55(2):131-4. https://doi.org/10.4103/0022-3859.52846

[3] Halkoaho A, Matveinen M, Leinonen V, Luoto K, Keränen T. Education of research ethics for clinical investigators with Moodle tool. BMC Med Ethics 2013; 14:53. https://doi.org/10.1186/1472-6939-14-53

[4] Steneck NH. Research ethics. Global research integrity training. Science 2013; 340(6132):552-3. https://doi.org/10.1126/science.1236373

[5] Woodcock JA, Willings MV, Marren P. Understanding the issue of informed consent in dental treatment. Prim Dent Care 2004; 11(2):41-5. https://doi.org/10.1308/135576104773711264

[6] Deolia SG, Prasad KW, Chhabra KG, Kalyanpur R, Kalghatgi S. An insight into research ethics among dental professionals in a dental institute, India - a pilot study. J Clin Diagn Res 2014; 8(9):ZC11-ZC14. https://doi.org/10.7860/JCDR/2014/10118.479

[7] Mallela KK, Rachit Walia R, TM CD, Das M, Sepolia SH, Sethi P. Knowledge, attitudes and practice about research ethics among dental faculty in the North India. J Int Oral Health 2015; 7(Suppl 2):52-6.

[8] Kakar H, Gambhir RS, Singh S, Kaur A, Nanda T. Informed consent: Corner stone in ethical medical and dental practice. J Family Med Prim Care 2014; 3(1):68-71. https://doi.org/10.4103/2249-4863.130284

[9] Taiwo OO, Kass N. Post-consent assessment of dental subjects' understanding of informed consent in oral health research in Nigeria. BMC Medical Ethics 2009; 10:11. https://doi.org/10.1186/1472-6939-10-11

[10] El-Dessouky HF, Abdel-Aziz AM, Ibrahim C, Mon Mi, Abul Fadl R, Silverman H. Knowledge, awareness, and attitudes about research ethics among dental faculty in the Middle East: A pilot study. Int J Dent 2011; 2011:694759. https://doi.org/10.1155/2011/694759

[11] Ghaderi M, Salimi M, Bolandhemmatan K. Awareness \& consideration faculty members and post-graduate students to ethical standards in research. Ethics Inf Technol 2016;10(4):85-7.

[12] Eskandarizadeh A, Mohammadzadeh I, Shahravan A, Bavafa M, Kakooei S, Torabi M. Prevention of secondary caries by a new antibacterial compound. DRJ 2020; 17(1):40-7.

[13] Ranjbar M, Dehghan Noudeh G, Hashemipour M-A, Mohamadzadeh I. A systematic study and effect of PLA/Al 2 O 3 nanoscaffolds as dental resins: mechanochemical properties. Artif Cells Nanomed Biotechnol 2019; 47(1):201-9. https://doi.org/10.1080/21691401.2018.1548472

[14] Hariharan S, Jonnalagadda R, Walrond E, Moseley H. Knowledge, attitudes and practice of healthcare ethics and law among doctors and nurses in Barbados. BMC Med Ethics 2006; 7:E7. https://doi.org/10.1 186/1472-6939-7-7

[15] Gopinath NM, John J, Senthilkumar E, Nagappan N. Knowledge awareness and attitude about research ethics among dental faculties in India. Contemp Dent Pract 2014; 15(5):608-13. https://doi.org/10.5005/jp-journals-10024-1587

[16] Macrae DJ. The Council for International Organizations and Medical Sciences (CIOMS) guidelines on ethics of clinical trials. Proc Am Thorac Soc 2007; 4(2):176-8. https://doi.org/10.1513/pats.200701-011GC

[17] Sanmukhani J, Tripathi CB. Ethics in clinical research: The Indian perspective. Indian J Pharm Sci 2011; 73(2):12530. https://doi.org/10.4103/0250-474x.91564

[18] World Medical Association. Declaration of Helsinki-Ethical Principles for Medical Research Involving Human Subjects. 2008. Available from: https://www.wma.net/en/30publications/10policies/b3/index.html. [Accessed on March 19, 2020].

[19] Stefánsson E, Atladóttir OY, Guðbjörnsson B. Are ethics rules too strict in retrospective clinical studies? Acta ophthalmologica 2008; 86(6):588-90. https://doi.org/10.1111/j.1755-3768.2008.01413.x

[20] Mukherjee A, Livinski AA, Millum J, Chamut S, Boroumand S, Iafolla TJ, et al. Informed consent in dental care and research for the older adult population: A systematic review. J Am Dent Assoc 2017; 148(4):211-20. https://doi.org/10.1016/j.adaj.2016.11.019

[21] Chima SC. Evaluating the quality of informed consent and contemporary clinical practices by medical doctors in South Africa: An empirical study. BMC medical ethics 2013; 14 Suppl 1(Suppl 1):S3.

https://doi.org/10.1186/1472-6939-14-S1-S3

[22] Kandeel N, El-Nemer A, Ali NM, Kassem H, El-Setouhy M, Elgharieb ME, et al. A multicenter study of the awareness and attitudes of Egyptian faculty towards research ethics: a pilot study. Empir Res Hum Res Ethics 2011; 6(4):99-108. https://doi.org/10.1525/jer.2011.6.4.99 